\title{
NUMERICAL INVESTIGATION OF HEAT TRANSFER FROM A POROUS PLATE WITH TRANSPIRATION COOLING
}

\author{
M.Kilic ${ }^{1^{*}}$
}

\begin{abstract}
The present study is focused on investigation of heat transfer from a porous plate by cooling of air and surface with transpiration cooling. Effects of Reynolds number of hot air $(\operatorname{Re}=3035,3200,3300,3580)$, effects of flow rate of water as a coolant ( $\left.\dot{\mathrm{m}}_{\text {water }}=0.000083,0.000116,0.000166,0.000249 \mathrm{~kg} / \mathrm{s}\right)$ on local wall temperature and cooling efficiency of porous flat and the system inside a rectangular channel with air as a hot gas stream and water as a coolant were investigated numerically. In this study; different from the literature, transpiration cooling was used as a cooling mechanism of air. It was observed from the results that increasing Reynolds number causes an increase on surface temperature and a decrease on cooling efficiency of porous plate and system. Increase of Reynolds number from $\mathrm{Re}=3035$ to 9430 causes a decrease of efficiency of the system of $13.7 \%$. Increasing water flow rate nine times causes not only a decrease on average surface temperature of $1.1 \%$ but also an increase of $6.5 \%$ on efficiency of porous plate and an increase of $19.1 \%$ on cooling efficiency of the system. Numerical results prepared by RNG k- $\varepsilon$ turbulence model generally have a good approximation with experimental results.
\end{abstract}

Keywords: Computational Fluid Dynamics, Heat Transfer, Porous Plate, Transpiration cooling

\section{INTRODUCTION}

Transpiration cooling processes involve simultaneously two different heat transfer mechanisms: conduction through a solid plus convection. In transpiration cooling process: fluid coolant is injected into porous matrix in the direction opposite to heat flux, at the same time absorbs the heat conducted into the solid matrix and transports heat flux through the convection passing pores, finally the coolant forms a thin film on the hot side surface to reduce the heat flux coming into the porous matrix and to cool the hot gas stream. This method has been used to protect solid surface exposed to high-heat-flux, high-temperature environments such as hypersonic vehicle combustors, liquid rocket thrusters, gas turbine blades, water oxidation technology, the nose of aerospace vehicles during the atmospheric re-entry phase of their flight. By using transpiration cooling not only solid surface can be protected but also temperature of hot gas can be reduced. So it can also be used to cool air. Therefore, this mechanism can be used as a cooling mechanism to cool the hot gas stream. Scope of transpiration cooling is shown in Figure 1.

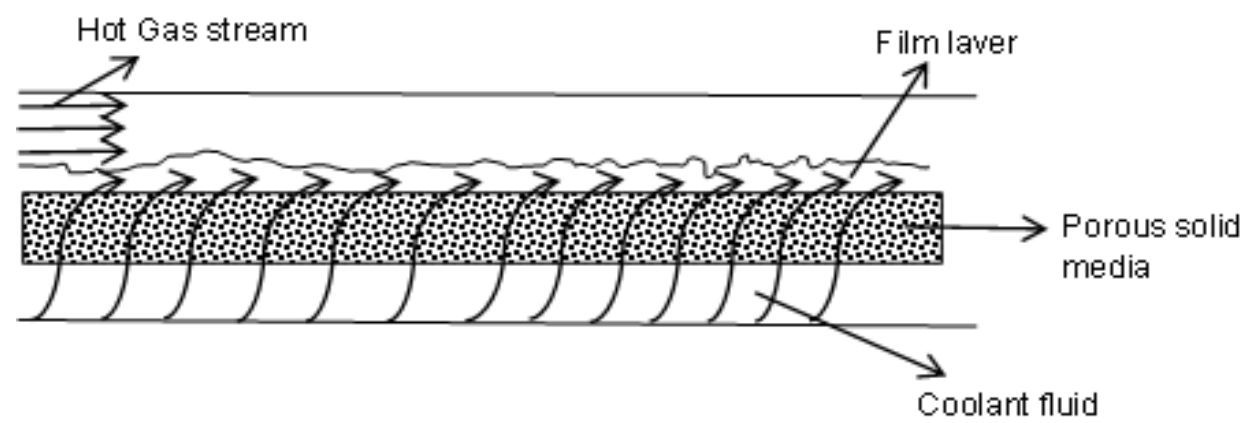

Figure 1. Scope of transpiration cooling

Many experimental and numerical investigations on transpiration cooling were performed and can be found in the literature. Polezhaev [1] numerically investigated transpiration cooling for critical high-temperature turbine blade. He showed that transpiration gas-cooled blade concept had a potential to achieve the goal of $60 \%$ This paper was recommended for publication in revised form by Regional Editor Derya Burcu Özkan ${ }^{1}$ Department of Mechanical Engineering, Adana Science and Technology University, Adana, TURKEY ${ }^{*} E$-mail address: mkilic@adanabtu.edu.tr Manuscript Received 16 June 2016, Accepted 23 August 2016 
thermal efficiency for a gas turbine power plant. Trevino and Medina [2] also obtained asymptotic and numerical results for the steady-state transpiration cooling of a thin porous flat plate in a laminar hot convective flow. The injection strength and its distribution along the plate are their parameters. They presented the asymptotic solution for the thermally thin wall regime and they showed that numerical results were in a good agreement with the asymptotic solution close to the asymptotic limits. Andoh and Lips [3] presented an analytical approach method for determining the fluid flow and the heat transfer characteristics in the porous matrices. The governing parameters were the volumetric heat transfer coefficient, the equivalent thermal conductivity of the material and fluid flow characteristics. They obtained that an increase of $90 \%$ of the value of volumetric heat transfer coefficient involves a decrease from $45 \%$ to $54 \%$ of the downstream face temperature. And the best conductivity material assures a best evacuation of heat flux, assuming a best thermal protection of the wall. They tested their method by simulation and compared with those of literature. They obtained good agreement with the previsions.

Cerri; Giovannelli; Battisti and Fedrizzi, [4] compared transpiration cooling to effusion cooling. The diameter, density and spacing of the holes, adiabatic film efficiency and the coolant air consumption were parameters of their numerical study. They showed that transpiration-cooled components have proved an effective way to achieve high temperatures and erosion resistance for gas turbines. Effusion cooling on the other hand is relatively simple and more reliable technique offering a continuous coverage of cooling air over the component's hot surfaces. Liu; Xiong; Jiang; Wang and Sun [5] investigated numerically the influence of the thermal conductivity and porosity of the porous wall and locally high heat fluxes on the hot surface and the location of a low porosity region within one and two layer porous walls on the temperature field. The local thermal nonequilibrium model was used to predict the temperature distribution in the solid. Their results showed that both the porosity and the thermal conductivity variations had a substantial effect on the temperature distribution. The reduction of the thermal conductivity and the decrease of the porosity reduced the influence of the outside boundary conditions to a thin layer. And the location of a low porosity obstructed region in the ceramic coating of the two-layer model with the bronze base matrix had a pronounced effect on the temperature field. He and Wang [6] studied on a simulation about one-dimensional and steady-state transpiration cooling problem with phase change numerically. Different heat flux and coolant injection were their parameters to analyze thickness of two-phase region and driving force of coolant injection. Their results showed that the thickness of the two-phase region does not vary with heat flux, when the plate is in vapor, two-phase and liquid phase, while the thickness is mainly influenced by coolant mass flow rate. And the pressure and capillary pressure at the bottom of the plate had the same trend so the capillary pressure was the main factor causing pressure change.

Huang; Zhu; Xiong and Jiang [7] investigated cooling of a sintered porous struts using transpiration cooling in scramjets numerically. Methane was used as coolant fluid. Different strut structure, material properties and coolant conditions were their parameters in their study. Main stream velocity was 2.5 Mach and temperature of it was $1920 \mathrm{~K}$. Their results showed that increasing the coolant blowing ratio improves the cooling effectiveness. The strut surface cooling effectiveness first increased and then decreased as the wedge angle increased. The strut surface temperature decreased as the material thermal conductivity increased. Shi and Wang [8] studied on an analytic solution of a simplified local thermal non-equilibrium model to optimize a porous structure which consists of two layered media. Their results indicated that the thermal conductivity and porosity of the second layer near the hot side is very important for the hot side temperature. And when the pressure difference is constant, the porosity of the first layer has notable effect on the coolant mass flow rate and when the coolant mass flow rate is constant the porosity of the first layer has a miner effect on the hot surface temperature. Under the condition of constant pressure or constant mass flow rate, the composition and porosity of the second layer have more important effects on the hot surface temperature than the first layer. Song; Lee and Sung [9] investigated the cooling enhancement by applying evaporative cooling to an air-cooled finned heat exchanger numerically. The heat exchanger is simplified as a channel filled with a porous media. Their results showed that when the surface is covered with thin water film, the temperature difference between the channel wall and the air becomes smaller due to the water evaporation from the fin surface and subsequent latent heat dissipation. The fin thickness and the fin pitch were taken as main parameters. Consequently, the cooling effect improves considerably compared with in the sensible cooler without water evaporation. The maximum cooling enhancement is by a factor of which is associated with the ratio between the latent heat of the water evaporation from the fin surface. And when the fin is not efficiently thick, the cooling enhancement by the evaporative cooling decreases since the fin efficiency drops due to the water evaporation from the surface. Leu; Jang and Chou [10] studied on analyzes the forced liquid film evaporation problem in a saturated non-Darcian porous 
medium numerically. Their parameters were porosity $\varepsilon$, inlet liquid Reynolds number Rel, inlet air Reynolds number Rea. Their results showed that the mass loss of liquid film due to evaporation is small and liquid consumption ratio is within $6 \%$. Lower Rel and higher $\varepsilon$ make liquid film higher interfacial temperature and mass concentration, thus enhance the heat and mass transfer performance across the film interface. And the influence of Rel on the heat and mass transfer performance of liquid film evaporation in porous media are more important than the influence of $\varepsilon$. Hsyan; Jer and Kuang [11] investigated the evaporation of liquid on steady, two-dimensional laminar mixed convection flows over a vertical plate in porous media numerically. They obtained the non-similar solution for the velocity, temperature and concentration distribution for several values of the Darcian resistance and buoyancy force parameters. Their results showed that while Darcian resistance approaches infinite, the convection term and boundary effect are not obvious. The latent and sensible heat of mixed convection is greater than that of forced convection. The evaporation of liquid will increase when Rak/Pex (Modified Rayleight number/Peclect number) is gradually increased. The magnitude of heat transfer rate on the wall is influenced by the temperature and concentration profile.

Maity [12] investigated the flow and heat transfer of a thin liquid film over an unsteady porous stretching sheet in presence of suction or injection numerically. Porosity, suction and injection velocity are his parameters. His results showed that the film thinning rate decreased with increase of the porosity of the porous medium. Increasing suction was responsible for quicker thinning of film whereas increasing injections slow downed the film thinning process. The temperature of the liquid film increased with increasing of suction velocity and decrease with increase of injection velocity when the sheet is heating. Xin; Rao; You; Song and Han [13] investigated distribution of temperature, pressure and saturation in transpiration cooling with coolant phase change and in convective boiling in porous media heated on both sides. They used water as a coolant. Particle diameter, porosity, coolant mass flow rate, and heat flux were $300 \mu \mathrm{m}, 0.35,0.2 \mathrm{~kg} / \mathrm{m} 2 \mathrm{~s}$, and $0.594 \mathrm{MW} / \mathrm{m} 2$. Their results showed that a countercurrent flow of vapor occurs, which can enhance heat transfer greatly due to the latent heat. In the two-phase region the solid temperature varies slightly while the fluid temperature varies dramatically especially near the interface between the two-phase flow region and the vapor region. In convective boiling heated on both sides, along the flow direction the temperature profile appears an N-shaped curve, the temperature in the single-phase increases, while the temperature in the two-phase region seems slightly increases firstly in a short distance and then decreases. Sun; Zhang; Xu and Zhong [14] investigated FC-72 flow boiling enhancement from the micro porous coating and wall confinement effect in mini channels. Particle diameter, coating thickness were their parameters. Their results showed that P50 (50 $\mu \mathrm{m}$ particle diameter) exhibits the highest enhancement ratio of $692 \%$, followed by P120 (120 $\mu \mathrm{m}$ particle diameter) and P20 (20 $\mu \mathrm{m}$ particle diameter) with relatively smaller enhancement of $596 \%$ and $424 \%$. Relative coating thickness $(\mathrm{tr}=\mathrm{tc} / \mathrm{dp})$ should not be less than 2-4. The optimum coating thickness was 4 for this application. Applying the micro porous coating in the mini channel provided prominent flow boiling heat transfer enhancement. With the optimum coating, the ONB wall superheat was reduced by $7.4 \mathrm{~K}$ and the boiling wall temperature could be lowered by $10.3 \mathrm{~K}$, while the maximum heat flux was increased by about $10.3 \mathrm{~K}$, while the maximum heat flux was increased by about $20 \%$. The heat transfer coefficient was 7-10 times those of the uncoated surface at various liquid mass fluxes. Jiang; Yu; Sun and Wang, [15] investigated turbulent flow and heat transfer in a rectangular channel without and with transpiration cooling experimentally and numerically. Their results showed that the transpiration cooling greatly increases the boundary layer thickness and reduces the wall skin friction and increasing coolant blowing ratio sharply reduced both the wall temperature and the convection heat transfer coefficient. Liu; Jiang; Jin and Sun [16] investigated the transpiration cooling mechanisms for thermal protection of a nose cone experimentally and numerically for various cooling gasses. In their study: they used air, nitrogen, argon, carbon dioxide and helium as a hot gas stream. Their results showed that the injection rate strongly influenced the cooling effectiveness. The increase of the main stream inlet Reynolds number dramatically reduced the cooling effectiveness. And the coolant thermos physical properties, especially specific heat, most strongly influenced the cooling effectiveness.

Liu; Jiang; Xiong and Wang [17] investigated the flow and heat transfer characteristic of transpiration cooling through sintered porous flat plates with particle diameters $\mathrm{dp}=40$ and $90 \mu \mathrm{m}$ experimentally and numerically with dry air as the coolant stream. They showed that the cooling effectiveness increased with increasing injection rate, the temperature distribution on the porous bronze plate was more uniform than that on the sintered stainless steel plates and the cooling performance for the porous wall with the smaller particle diameters was better. Arai and Suidzu [18] investigated experimentally effects of the porous ceramic coating 
material such as permeability of cooling gas, thermal conductivity and adhesion strength. The mixture of $8 \mathrm{wt} . \%$ yttria-stabilized zirconium and polyester powders was employed as the coating material, in order to deposit the porous ceramic coating onto Ni-based super alloy substrate in their study. They showed that porous ceramic coating has superior permeability for cooling gas and transpiration cooling system for gas turbine could be achieved by using porous ceramic coating. He; Wang; Xu and Wang [19] investigated new conversation equation for mass, momentum and energy to describe the performances of fluid flow, heat absorption and phase change in porous matrix. Their model's main differences from previous models are firstly, considering the compressibility of vapor in the momentum and energy equations, secondly, adding a term of the momentum transfer caused by liquid phase change into the momentum equation of vapor and liquid phases in two-phase region, finally in the energy equation of two-phase region, taking the variations of temperature and pressure into account. Their results showed that with an increase in heat flux and decrease in coolant mass flow rate the temperature difference over the two-phase region falls and a higher external heat flux or lower coolant mass flow rate will accelerate the phase change process and increase he area of two-phase region and vapor region. Wang; Zhao; Wang; Ma and Lin [20] investigated the effect of different mainstream temperature, Reynolds numbers, and coolant injection ratio on transpiration cooling of the wedge shape nose cone with an equal thickness porous wall using liquid water as coolant. They obtained that the average temperature over the transpiration area falls with an increase in the coolant injection ratio, whereas the average cooling effectiveness rise and There is an optimal injection rate, at which the coolant passing through pores with liquid state when the driving force for the coolant injection is the minimum and the cooling effectiveness is high. Tsai; Lin; Wang; Lin; Su and Yang [21] investigated the transient cooling process in a sudden-expansion channel with the injection of cold air from the porous bottom wall experimentally. They categorized flow features to four cooling patterns; the recirculation pattern, the elevated recirculation pattern, the transpiration pattern and film pattern.

Langener; Wolserdorf; Selzer and Hald [22] investigated transpiration cooling applied to flat $\mathrm{C} / \mathrm{C}$ material under subsonic main-flow conditions. In their study; main-stream Mach number ranged from $\mathrm{Mg}=0.3$ 0.7 and totals temperature was $523 \mathrm{~K}$. Air, argon and helium were used as coolants. They showed that thickness of sample and main stream total temperature did not affect the cooling efficiency. The coolant used and its specific capacity was the most influential parameter for the cooling efficiency. Zhao; Wang; Ma; Lin; Peng; Qu and Chen [23] presented a supersonic experimental investigation on transpiration cooling of a nose cone model with unequal thickness walled configuration using liquid water as coolant. Their experiments showed that ice cake appeared at the nose cone surface at main stream Mach number 2.0, stagnation pressure $174 \mathrm{kPa}$ and mass flow rate $2.286 \mathrm{~kg} / \mathrm{s}$ with an enthalpy $300 \mathrm{~kJ} / \mathrm{s}$. But ice cake disappeared when the stagnation pressure and enthalpy rise to $305 \mathrm{kPa}$ and $1300 \mathrm{~kJ} / \mathrm{kgm}$ and the design of unequal thickness walled configuration nose cone is effective to solve the key issue of cooling stagnation point. So optimization of wall thickness should be based on mainstream condition, permeability and sample structure. Tsai and Lee [24, 25] investigated the correlation between superheat levels and heat fluxes when used sintered powder structures as wicks. Their parameters were $45 \mu \mathrm{m}, 75 \mu \mathrm{m}, 150 \mu \mathrm{m}$ of powder sizes and powder shapes of spherical, dendritic. Their results showed that smaller powders structures achieved higher effective thermal conductivities for both powder shapes. Spherical powder structures achieved twice the effective thermal conductivity of dendritic powder ones for each powder size. He; Guan; Gurgenci; Hooman; Lu and Alkhedhair [26] investigated performance of evaporative cooling with cellulose and Polyvinyl Chloride (PVC) corrugated media experimentally. The heat and mass transfer and pressure drop across the two media with three thicknesses $(100,200,300 \mathrm{~mm})$ were studied. Their results showed that the pressure drop range of the cellulose media is 1.5-101.7 Pa while the pressure drops of the PVC media are much lower with the range of 0.9-49.2 Pa, depending on the medium thickness, air velocity and water flow rate. The cooling efficiency of the cellulose media vary from $43 \%$ to $90 \%$ while the cooling efficiency of the PVC media are $8 \%$ to $65 \%$ depending on the medium thickness and air velocity.

As seen from the literature survey, there are numerous studies related with the design and simulation of systems with transpiration cooling. Most of these previous investigations can be divided into two categories. The first group focused on analyses of the characteristics of the boundary layer, turbulent or laminar flow in transpiration conditions. The second group focused on transpiration cooling effectiveness at high pressure and temperature to simulate practical conditions. However, there are few studies of controlling the temperature of hot gas stream and flow rate of coolant to enhance heat transfer by using transpiration cooling. The objective of this study is to investigate the local wall temperature and cooling effectiveness distribution along the surface of a 
porous flat plate with air as a hot gas stream and water as a coolant to figure out the influence of Reynolds number of hot gas stream and different water flow rate of water on heat transfer.

\section{PRELIMINARY DEFINITIONS}

In this application there is a porous plate in a rectangular channel, this porous plate is wetted by water of which inlet temperature is $\mathrm{T}_{\text {water }}=22{ }^{\circ} \mathrm{C}$. Air enters in the channel with some different velocities. For this application dry air was used as a hot gas stream and all Reynolds numbers were chosen bigger than 3000 . So it can be assuming that it is a turbulent flow. Mean film temperature in the channel is calculated as;

$$
T_{\text {avg }}=\frac{T_{\text {airin }}+T_{\text {surface }}}{2}
$$

where $\mathrm{T}_{\text {airin }}$ is the inlet temperature of air, $\mathrm{T}_{\text {surface }}$ is the average surface temperature of porous plate. So it can be calculated, as explained by Mills [27] and Cengel and Ghajar [28], some physical properties of air by using thermodynamics tables as; $\rho$ is the density of air, $\mathrm{Cp}$ specific heat of air, $\gamma$ is the kinematic viscosity, Pr is the Prandtl number and Sc Schmidt number. So Stanton number with zero porosity can be calculated as;

$$
S t^{*}=0.0296(\operatorname{Re})^{-0.2}(\operatorname{Pr})^{-2 / 3}
$$

And convective heat transfer coefficient with zero-mas-transfer will be;

$$
h c^{*}=\rho \cdot V_{a i r} \cdot C p \cdot S t^{*}
$$

where $\rho$ is the density of air, $\mathrm{V}_{\text {air }}$ is air velocity, $\mathrm{Cp}$ specific heat of air and $\mathrm{St}^{*}$ is Stanton number. So mass transfer driving force is;

$$
B_{m}=\frac{\dot{m}_{e v}-\dot{m}_{s}}{\dot{m}_{s}-1}
$$

where $\dot{\mathrm{m}}_{\mathrm{ev}}$ is mass fraction of water vapor at channel flow and $\dot{\mathrm{m}}_{\mathrm{s}}$ is mass fraction of water vapor at surface. And mass transfer St number can be calculated as;

$$
S t^{*}{ }_{\text {mass }}=0.0296(\operatorname{Re})^{-0.2}(S c)^{-2 / 3}
$$

So the zero mass transfer limit conductance will be;

$$
g^{*}{ }_{\text {mass }}=\rho \cdot V_{a i r} \cdot S t^{*}{ }_{\text {mass }}
$$

where $\rho$ is the density of air, $\mathrm{V}_{\text {air }}$ is air velocity and $\mathrm{St}^{*}$ mass is the mass transfer Stanton number. And the mass transfer conductance is;

$$
g_{\text {mass }}=g_{\text {mass. }}^{*} \frac{\ln \left(1+B_{m}\right)}{B_{m}}
$$

where $\mathrm{g}^{*}{ }_{\text {mass }}$ is the zero mass transfer limit conductance, $\mathrm{B}_{\mathrm{m}}$ is the mass transfer driving force. So mass flow rate of evaporated water is; 


$$
\dot{m}_{e v}=g_{\text {mass }} . B_{m}
$$

Then heat transfer blowing parameter is;

$$
B_{h}=\frac{\dot{m}_{e v} \cdot C p}{h c^{*}}
$$

where $\dot{\mathrm{m}}_{\mathrm{ev}}$ is the mass flow rate of evaporated water, Cp specific heat of air and hc ${ }^{*}$ is convective heat transfer coefficient with zero-mas-transfer. And convective heat transfer coefficient for surface of porous plate is;

$$
h_{c}=h_{c}^{*} \cdot \frac{B_{h}}{\exp \left(B_{h}\right)-1}
$$

So energy balance equation on the surface of porous plate is;

$$
\dot{m}_{\text {air }} .\left(h_{\text {airout }}-h_{\text {airin }}\right)=\dot{m}_{\text {water }} .\left(h_{\text {waterin }}-h_{f g}-h_{\text {waterout }}\right)
$$

where $\dot{\mathrm{m}}_{\text {air }}$ is the mass flow rate of air, $\mathrm{h}_{\text {airout }}$ is the outlet enthalpy of air, $\mathrm{h}_{\text {airin }}$ is the inlet enthalpy of air, $\dot{\mathrm{m}}_{\text {water }}$ is the mass flow rate of water, $h_{\text {waterin }}$ is the inlet enthalpy of water, $h_{\text {waterout }}$ is the outlet enthalpy of water, and $h_{f g}$ is the latent heat of water. Convection heat transfer can be calculated as;

$$
\dot{q}_{\text {conv }}=\dot{m}_{\text {water }} \cdot\left(h_{f g}+h_{\text {waterout }}-h_{\text {waterin }}\right)=h_{c} \cdot A \cdot\left(T_{\text {air }}-T_{\text {surafce }}\right)
$$

where $\dot{\mathrm{m}}_{\text {water }}$ is the mass flow rate of water, $\mathrm{h}_{\text {waterin }}$ is the inlet enthalpy of water, $\mathrm{h}_{\text {waterout }}$ is the outlet enthalpy of water, $h_{f g}$ is the latent heat of water, $h_{c}$ is the convective heat transfer coefficient for surface of porous plate, $A$ is surface area of porous plate, $\mathrm{T}_{\text {air }}$ is the temperature of air and $\mathrm{T}_{\text {surface }}$ is the average surface temperature of porous plate. Conduction heat transfer from porous plate to water will be;

$$
\dot{q}_{\text {cond }}=\dot{m}_{\text {water }} \cdot\left(h_{\text {surfece }}-h_{\text {waterin }}\right)
$$

where $\dot{\mathrm{m}}_{\text {water }}$ is the mass flow rate of water, $\mathrm{h}_{\text {surface }}$ is the enthalpy of water at surface temperature, $\mathrm{h}_{\text {waterin }}$ is the inlet enthalpy of water at inlet temperature. So cooling efficiency of the porous plate, shows protecting degree of main surface by decreasing surface temperature with using porous plate, is;

$$
\eta=\frac{T_{\text {surface }}-T_{\text {airin }}}{T_{\text {water }}-T_{\text {airin }}}
$$

where $T_{\text {surface }}$ is the average surface temperature of porous plate, $T_{\text {airin }}$ is the inlet temperature of air, $T_{\text {water }}$ is the inlet temperature of water. And cooling efficiency of the system, shows cooling degree of air with using this system, will be;

$$
\eta_{\text {sys }}=\frac{T_{\text {airin }}-T_{\text {airout }}}{T_{\text {airin }}-T_{\text {surface }}}
$$

where $T_{\text {airin }}$ is the inlet temperature of air, $T_{\text {airout }}$ is the outlet temperature of air, $T_{\text {surface }}$ is the average surface temperature of porous plate. 


\section{NUMERICAL MODEL}

FLUENT ANSYS 14.0 simulation program was used for numerical analysis. Channel dimensions were $880 \times 220 \times 10 \mathrm{~mm}$. At beginning air as a hot gas stream entered the channel at different temperature. These temperatures were changed according to the heat flux. Air entered the channel at different speeds according to Reynolds Number of hot air. Water as a coolant entered from bottom of the porous plate at $22{ }^{\circ} \mathrm{C}$. When water reaches the hot side of porous plate it evaporates and it cools the surface by getting latent heat from the surface and mixed with the air stream while cooling air too. By decreasing surface temperature main surface can be protected against high heat flux. Addition to this cool air process can also be used for many industrial applications, space researches and defense applications. Model geometry and computational domain are shown in Figure 2-3.

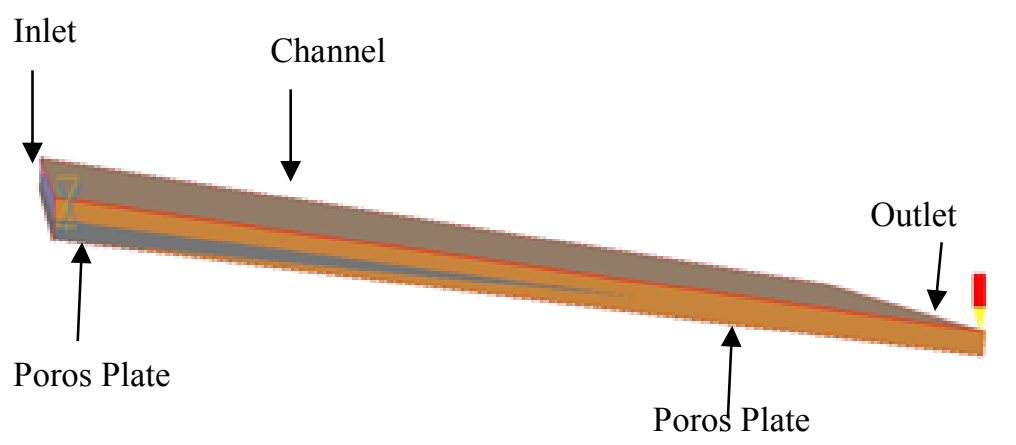

Figure 2. Model Geomerry

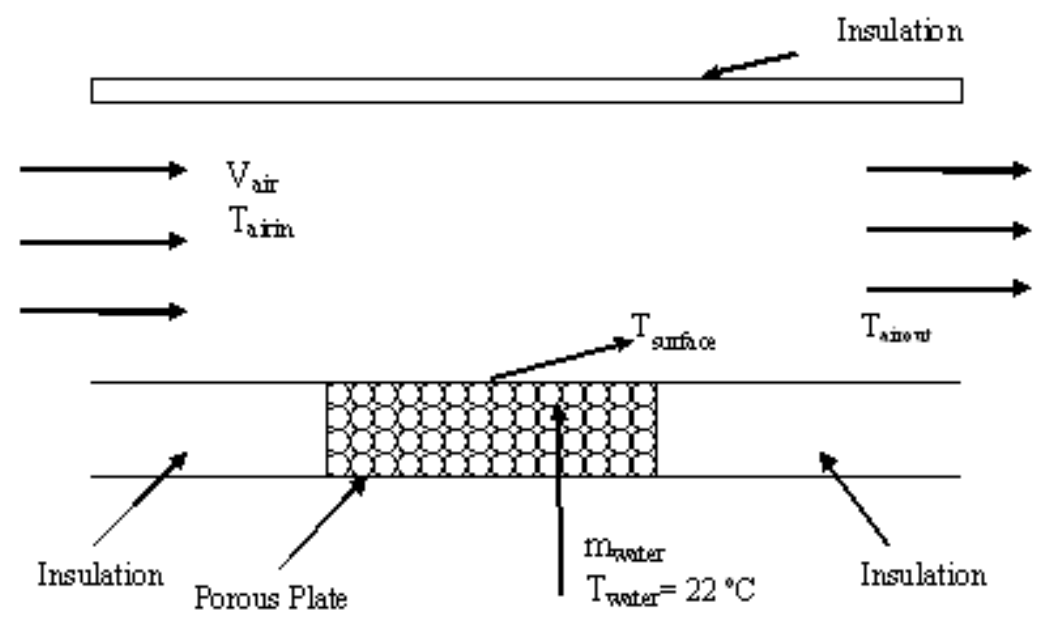

Figure 3. Computational Domain

We studied different number of mash structure $(464.640,619.520,774.400,929.280$ elements) for our applications. We prepared mash structure according to flow conditions. In order to get more precise numerical results, we increased mash numbers in some region as surface of porous plate, inlet and outlet of channel and near wall regions of channel. Minimum orthogonal quality is 1 and minimum aspect ratio is 1.12 . It is observed that numerical geometry was independent from sweep number and cell number when sweep number was 600 and cell number was 619.520. A graph of grid numbers for grid independence was shown in Figure 4.

The calculation continued for about 600 more iterations after the maximum residuals for all the dependent variables were less than $10^{-5}$, the overall energy and mass balances were less than $10^{-3}$. Boundary conditions used in numerical study are shown in Table 1. 


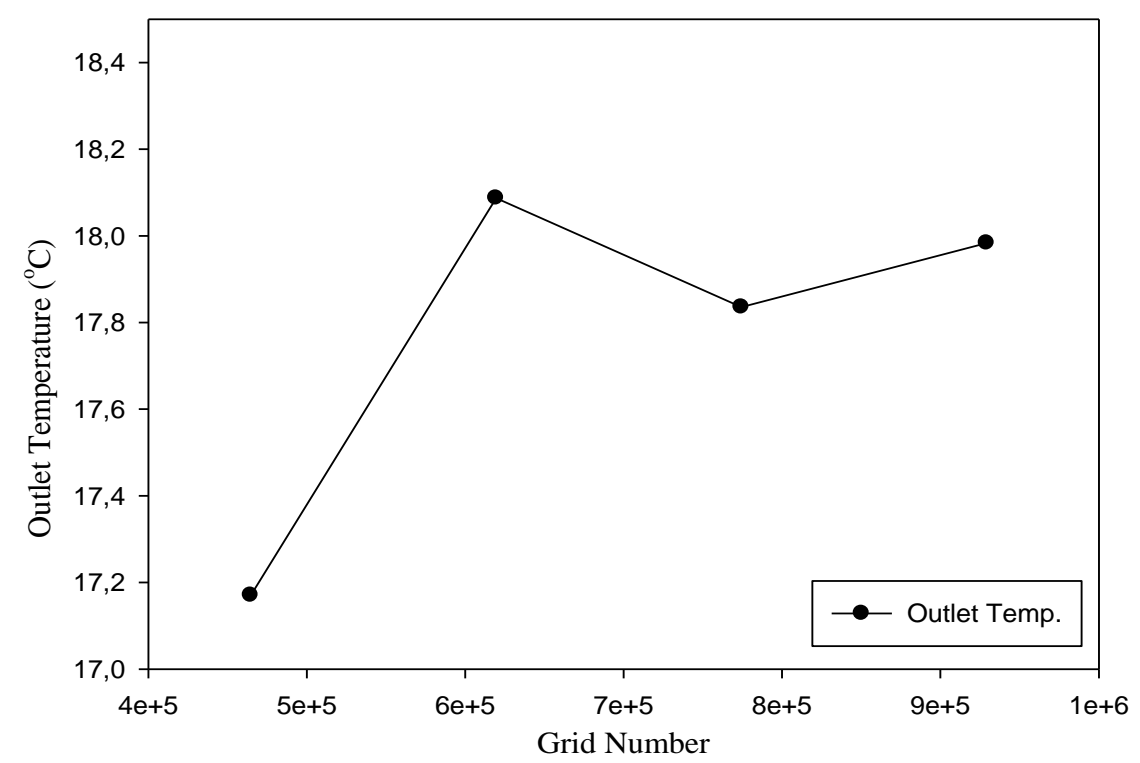

Figure 4. Grid Numbers for grid independence

Table 1. Boundary Conditions

\begin{tabular}{|c|c|c|c|c|}
\hline & $\mathrm{U}$ & v & W & $\mathrm{T}$ \\
\hline Air Inlet & $U=U_{\text {itlet }}$ & $V=0$ & $W=0$ & $T=T_{\text {ativinet }}$ \\
\hline Water inlet & $U=0$ & $V=0$ & $W=0$ & $T=T_{\text {wateriziet }}$ \\
\hline Porous Plate & $U=0$ & $V=0$ & $W=0$ & $q^{\prime \prime}=q_{\text {costi }}$ \\
\hline Outlet & $\frac{\partial U}{\partial x}=0$ & $\frac{\partial V}{\partial x}=0$ & $\frac{\partial W}{\partial x}=0$ & $T=$ Tout \\
\hline Front and back wall & $\mathrm{U}=0$ & $V=0$ & $W=0$ & $\frac{\partial T}{\partial y}=0$ \\
\hline Top wall & $\mathrm{U}=0$ & $V=0$ & $W=0$ & $\frac{\partial T}{\partial z}=0$ \\
\hline
\end{tabular}

The Navier-Stokes equations were solved with several turbulence models including the Standard k- $\varepsilon$ model, RNG k- $\varepsilon$ model, Realizable k- $\varepsilon$ model and SST k- $\omega$ model to predict the thermal and fluid characteristics of porous plate subjected to transpiration cooling. The values of $\mathrm{y}+$ were less than 2.5 along the walls. Validation of turbulence model with experimental results was shown in Figure 5. It was seen that RNG k- $\varepsilon$ model best represents the general trends of the hot air temperatures and surface temperature of porous plate.

After forming a model geometry and mash structure, independent from sweep numbers and cell numbers, boundary conditions were applied for heat transfer from the surface with transpiration cooling. A flow chart for numerical and theoretical methods was shown in Figure 6.

\section{RESULTS AND DISCUSSION}

In this section, numerical results were presented for different Reynolds number of hot gas stream, and mass flow rate of water. Numerical results were also compared and verified with experimental results.

\section{Effect of Reynolds number of hot gas stream (Air)}

Numerical analysis is conducted for different Reynolds number $(\operatorname{Re}=3035,3200,3300,3580,6500$ and 9430$)$ at $\mathrm{T}_{\text {airinlet }}=77^{\circ} \mathrm{C}$, particle diameter $\mathrm{D}_{\mathrm{p}}=200 \mu \mathrm{m}$ and $\dot{\mathrm{m}}_{\text {water }}=0.000083 \mathrm{~kg} / \mathrm{s}$. Velocity profile of hot gas stream (air) were chosen in turbulent flow regime with low Reynolds number because it is planned to see effect of porous 
plate, channel walls and coolant on heat transfer precisely. Temperature contours for $\operatorname{Re}=3035$ and 9430 were shown in Figure 7.

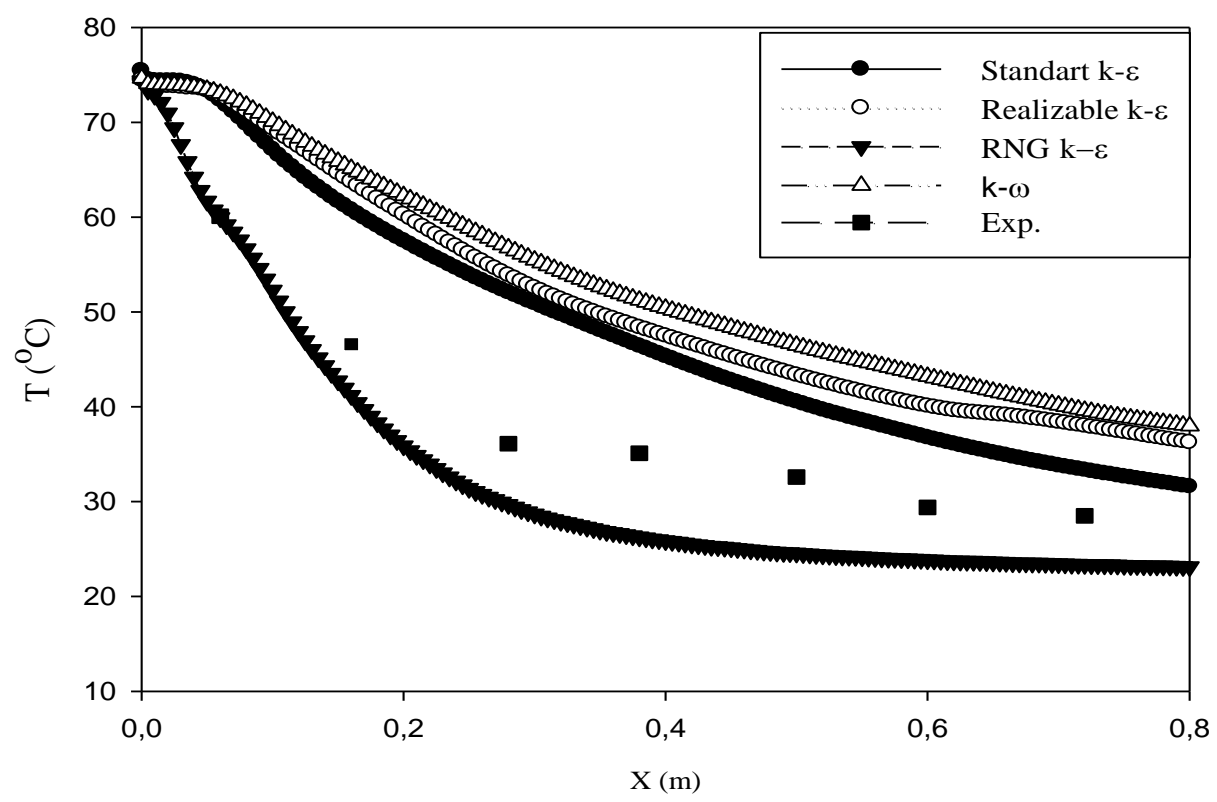

Figure 5. Validation of turbulence models with experimental results

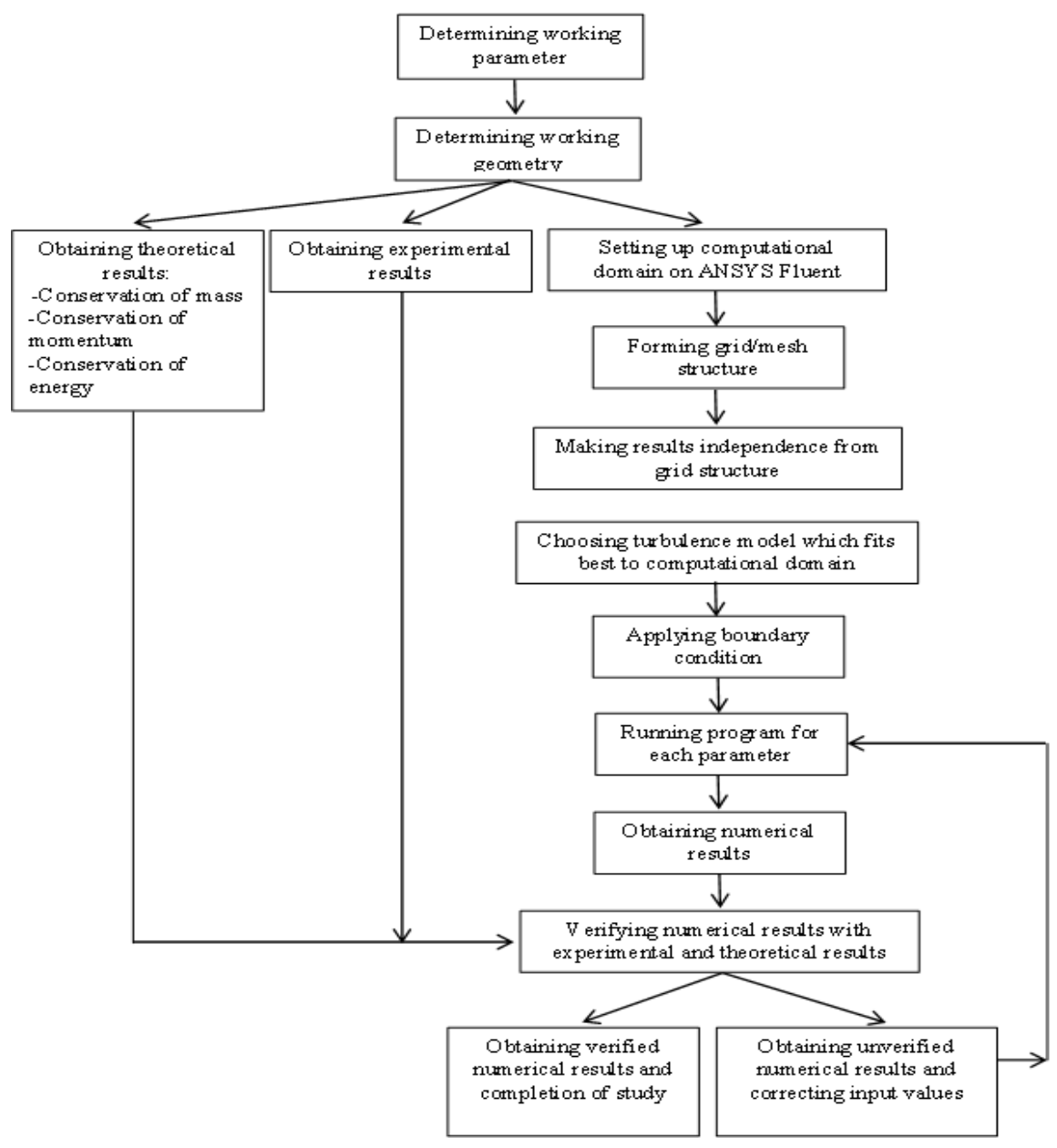

Figure 6. Flow chart for numerical and theoretical methods 


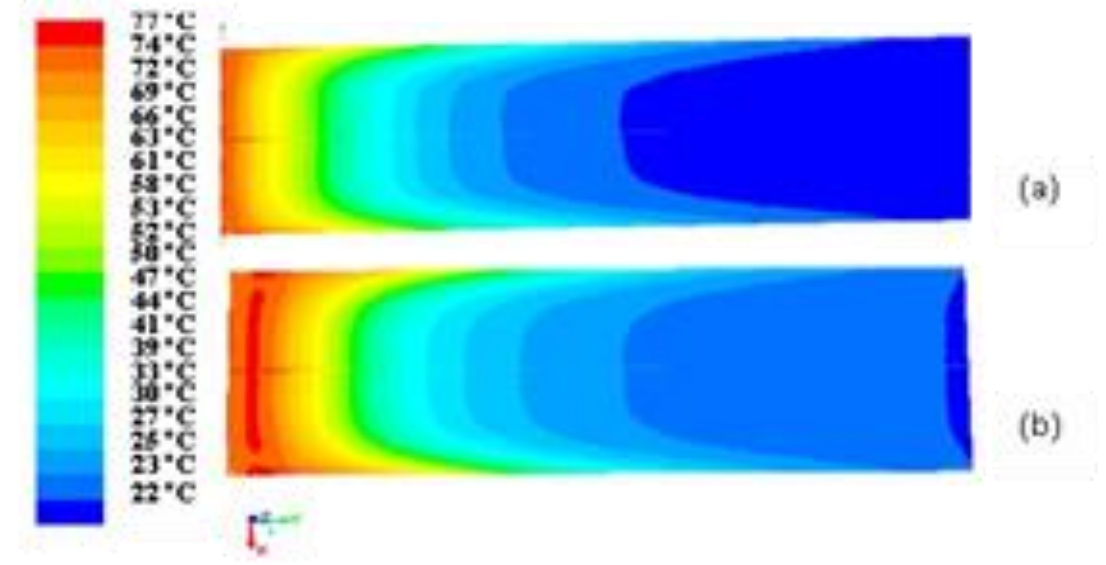

Figure 7. Temperature contours for (a) $\mathrm{Re}=3035$ and (b) $\mathrm{Re}=9430$

It can be seen that effect of Reynolds number of hot air can be detected easily at the inlet region of porous plate for higher Reynolds number according to lower Reynolds number. Surface temperature is higher at regions near to the walls, because fluid velocity near to the walls is low. Increasing Reynolds number 3 times causes a slight increase of $1.4 \%$ on average surface temperature. For different Reynolds number, temperature values of surface were shown in Figure 8.

Effect of Reynolds number can be seen clearly at the inlet region of porous plate. But cooling of air along the porous plate causes a sudden decrease on temperature and later on a gradually slight decrease on surface temperature up to the end of porous plate. Temperature difference is minimum at the outlet region of porous plate for different Reynolds number. There is not a significant difference on surface temperature and cooling efficiency for different Reynolds number we used at the end of porous plate. In this study, Reynolds numbers were chosen in a narrow gap to see effect of Reynolds number near to optimum value. Because of the velocity of air, surface temperature is decreasing sharply up to $\mathrm{x}=0.28 \mathrm{~m}$ but after that point there is not a prominent difference on surface temperature. Cooling efficiencies of porous plate for different Reynolds number were shown in Figure 9.

Difference of average cooling efficiency of porous plate, for $\mathrm{Re}=3035$ and $\mathrm{Re}=9430$, is $7.9 \%$. So increasing Reynolds number causes an increase on surface temperature and a decrease on cooling efficiency of porous plate. Cooling efficiencies of system for different Reynolds number were shown in Figure 10.

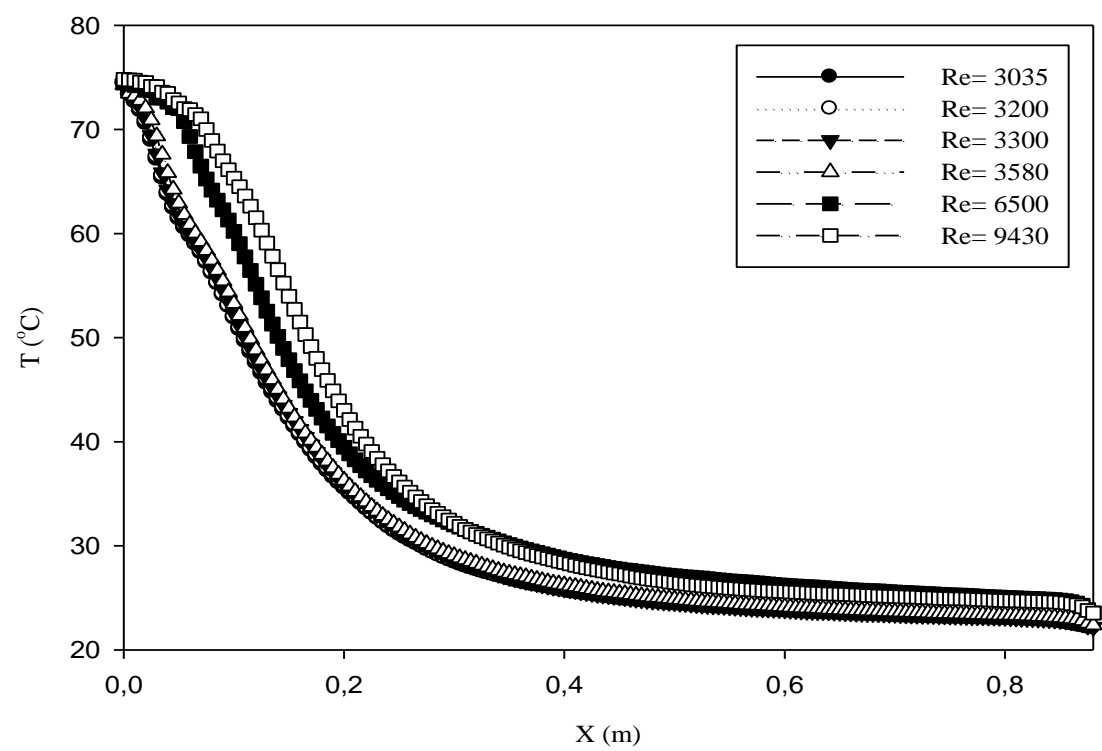

Figure 8. Surface temperature for different Reynolds number 


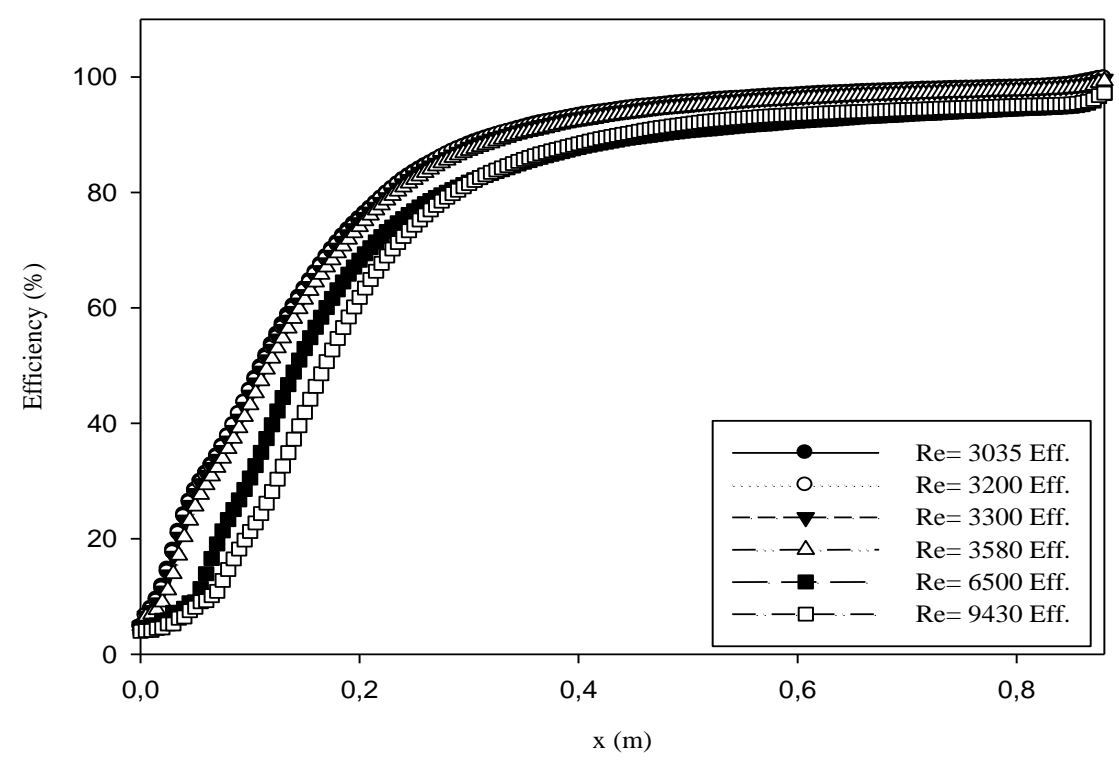

Figure 9. Cooling efficiency of porous plate for different Reynolds number

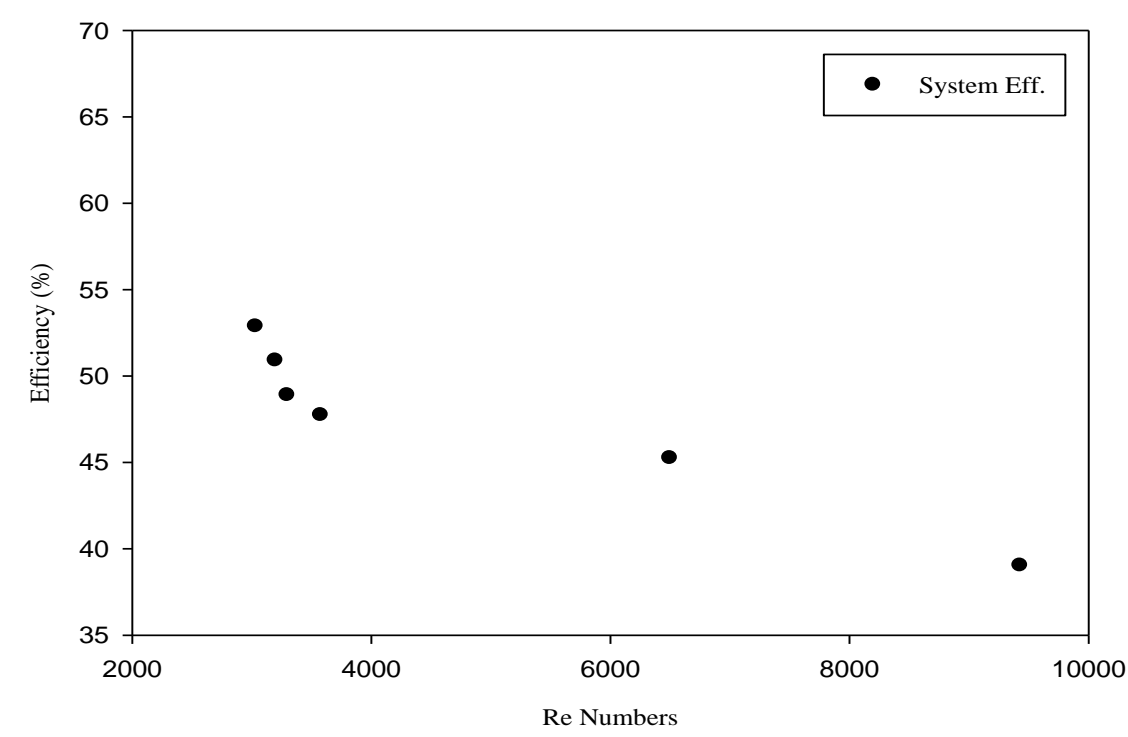

Figure 10. Cooling efficiency of system for different Reynolds number

Increasing Reynolds number causes a slight decrease on efficiency of the system for lower Reynolds number. Trend of this decrease increases for higher Reynolds number. Increase of Reynolds number from $\operatorname{Re}=3035$ to 9430 causes a decrease of efficiency of the system of $13.7 \%$. Decreasing trend of the efficiency of the system also increases gradually between $\mathrm{Re}=3035$ and 9430 . The reason of this decrease on the efficiency of the system is that increasing air velocity (while increasing Reynolds number) causes a decrease on heat convection between hot air and water on the surface of porous plate.

\section{Effect of mass flow rate of water}

Numerical analysis were conducted for different water flow rate for $\mathrm{Re}=3300$, particle diameter $\mathrm{D}_{\mathrm{p}}=200 \mu \mathrm{m}$ and $\mathrm{T}_{\text {inlet }}=77^{\circ} \mathrm{C}$. Temperature contours for $\dot{\mathrm{m}}_{\text {water }}=0.000116 \mathrm{~kg} / \mathrm{s}$ and $\dot{\mathrm{m}}_{\text {water }}=0.000747 \mathrm{~kg} / \mathrm{s}$ were shown in Figure 11. Variation of surface temperature for different water flow rates were shown in Figure 12.

It can be seen that increasing water flow rate caused a slight decrease on surface temperature and cooling efficiency of porous plate for the applied values of this study. Because flow rate of water was slightly changed to determine the optimum value of water flow rate. By using transpiration cooling surface temperature 
can be decreased of $13.8 \%$ from $77^{\circ} \mathrm{C}$ to $28.6^{\circ} \mathrm{C}$. But increasing water flow rate nine times causes a decrease on average surface temperature of $1.1 \%$.

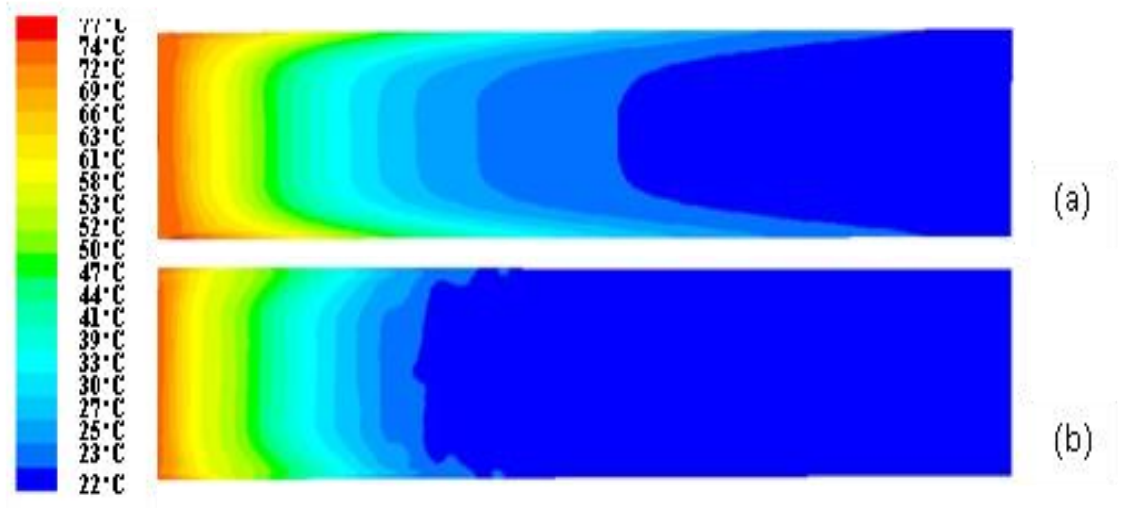

Figure 11. Temperature contours for (a) $\dot{\mathrm{m}}_{\text {water }}=0.000116 \mathrm{~kg} / \mathrm{s}$ and (b) $\dot{\mathrm{m}}_{\text {water }}=0.000747 \mathrm{~kg} / \mathrm{s}$

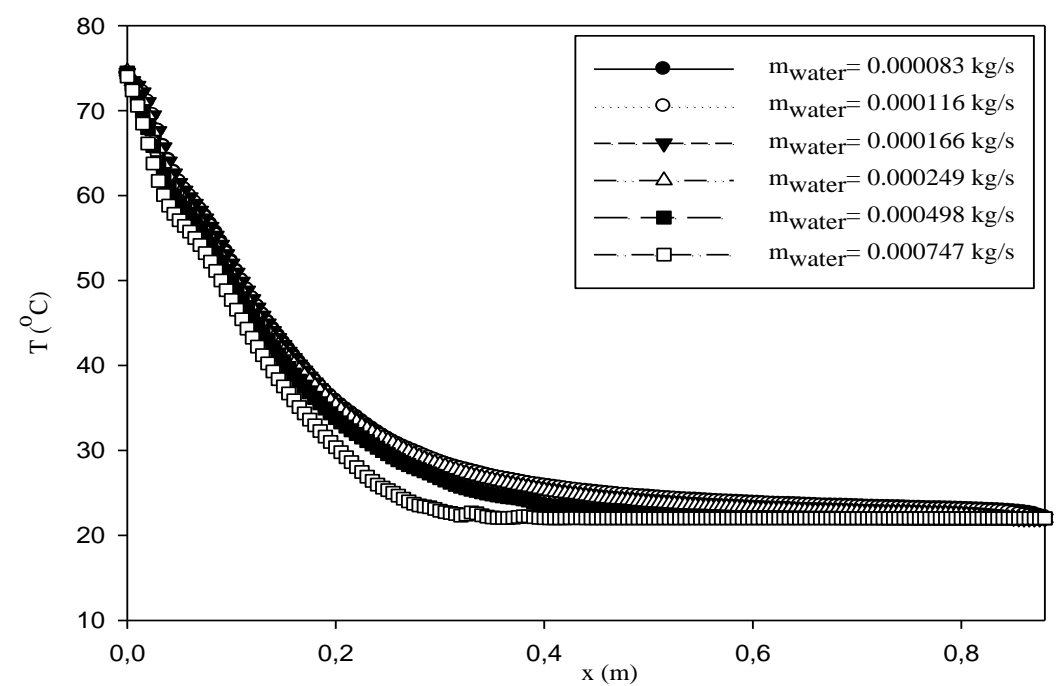

Figure 12. Variation of surface temperature for different water flow rates

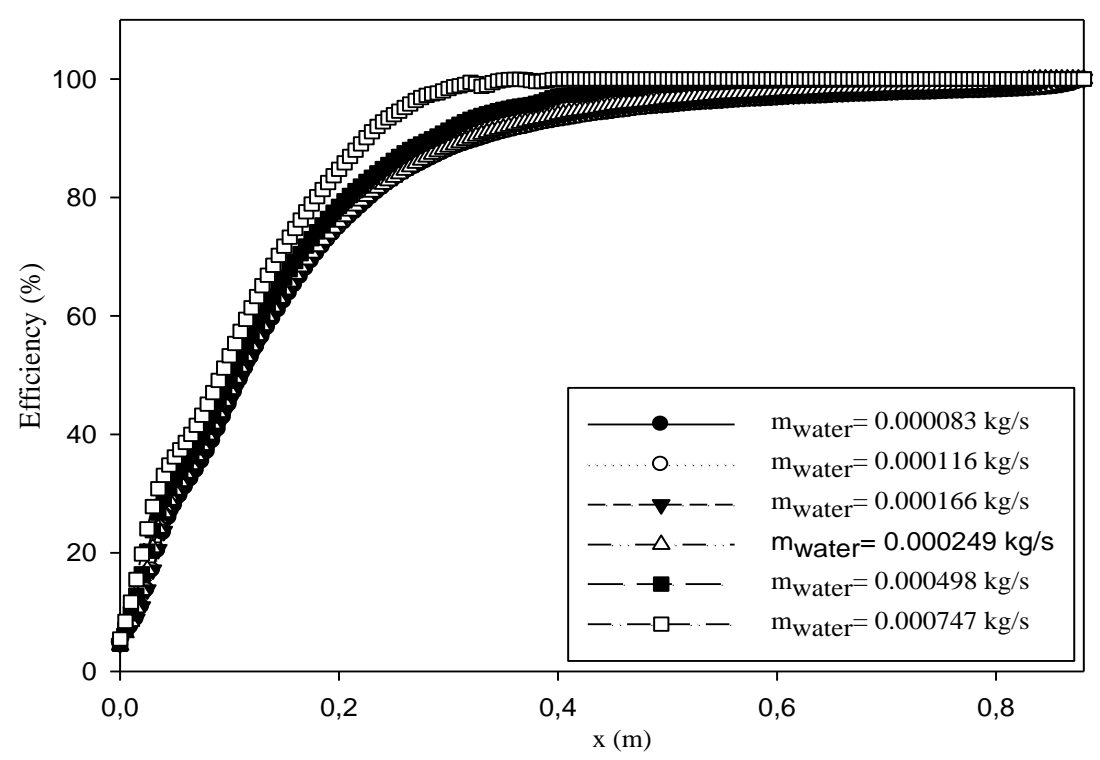

Figure 13. Cooling efficiency of porous plate for different water flow rate 


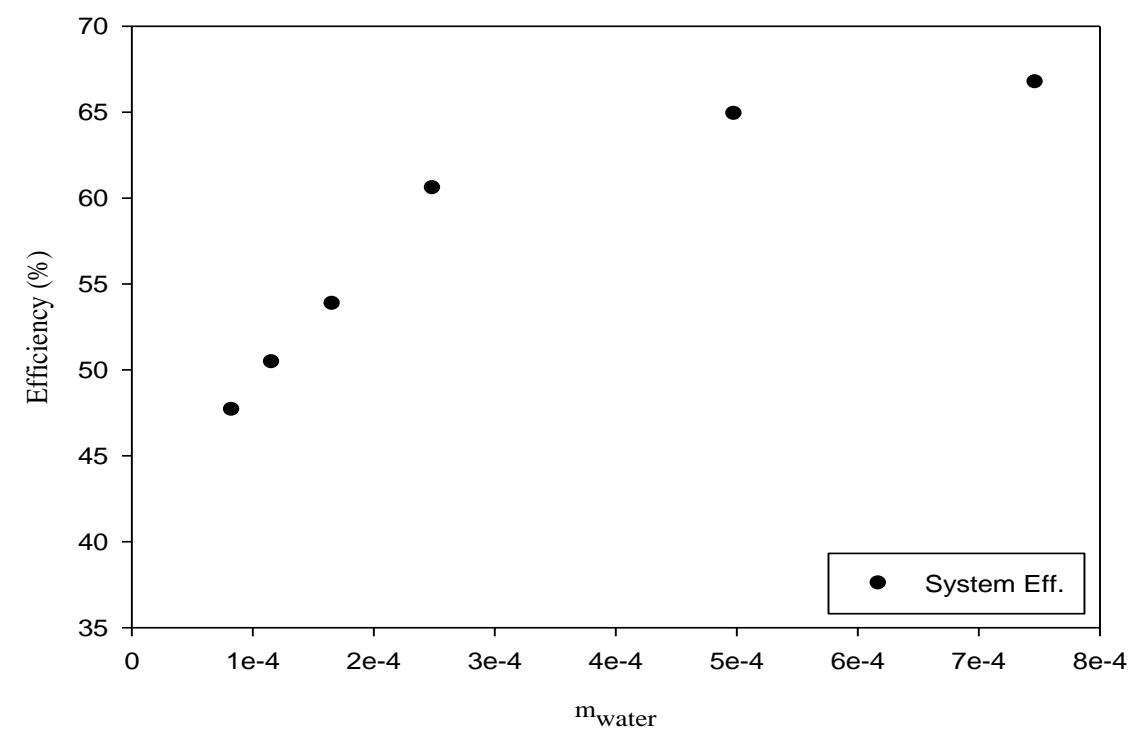

Figure 14. Cooling efficiency of system for different water flow rate

The higher injection rates result in further increase of the cooling effectiveness of porous plate. The difference of cooling efficiency of porous plate for different flow rates decreased at the end of the porous plate. Because air temperature also decreases at that region. Cooling efficiency of porous plate for different water flow rate was shown in Figure 13.

Increasing water flow rate nine times also causes an increase of $6.5 \%$ on efficiency of porous plate. Cooling efficiency of the system for different water flow rate was shown in Figure 14.

Increasing water flow rate as a coolant causes a prominent increase on cooling efficiency of the system. Increasing water flow rate nine times causes an increase of $19.1 \%$ on cooling efficiency of the system. Because increasing flow rate of water not only causes an increase on the quantity of evaporated water and amount of heat taken from the air but also decrease of temperature of air and surface. But increasing trend of cooling efficiency of the system is higher for lower flow rate than higher flow rate. Because, increasing water flow rate too much causes not only an increase on thickness of film on surface but also a decrease on amount of evaporated water.

\section{Validation of numerical results with experimental results}

Validation of numerical results was shown with some experimental results. Numerical results generally have a good approximation with experimental results. It was also observed that 4 th and 5 th group thermocouple

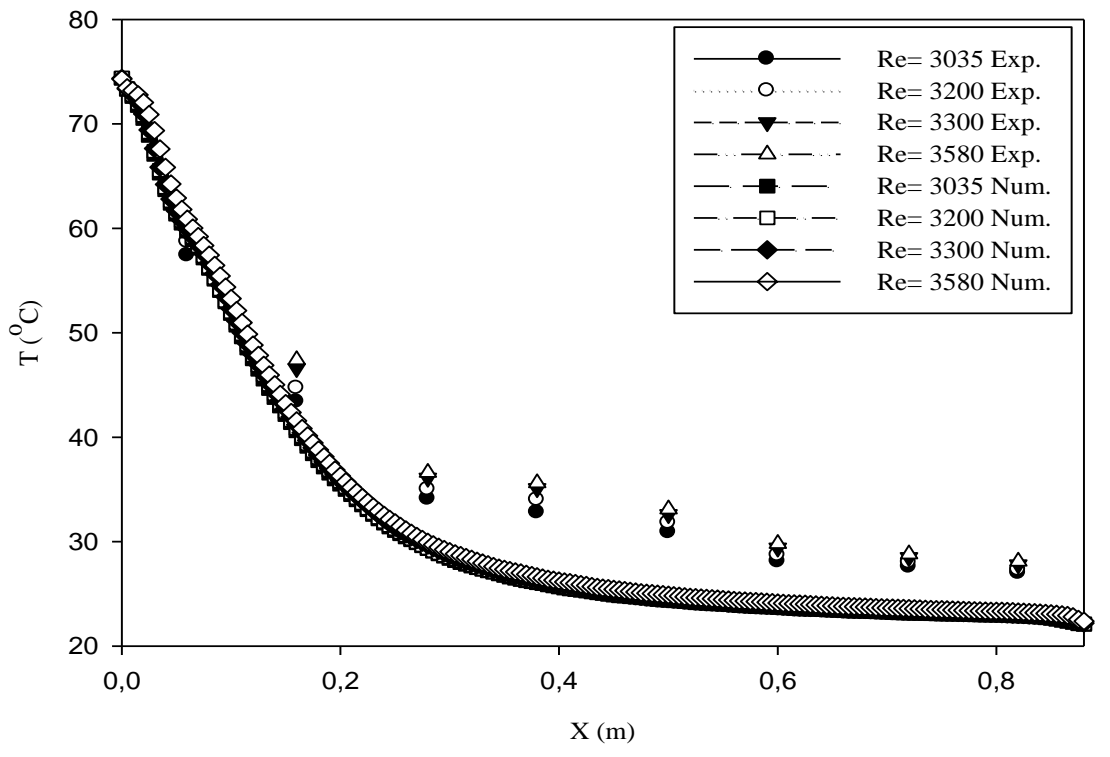

Figure 15. Comparison of experimental and numerical values of surface temperature for different Reynolds number 


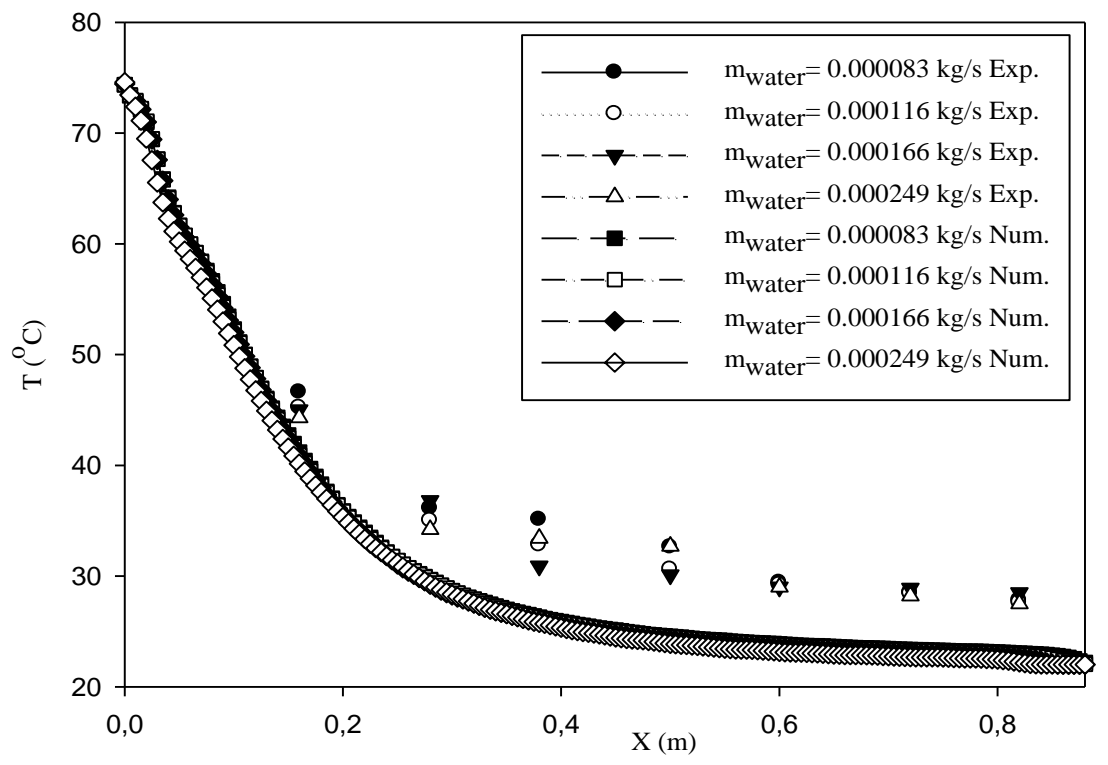

Figure 16. Comparison of experimental and numerical values of surface temperature for different water flow rate

showed higher temperature according to numerical result. It is thought that the reason of this is dry point of porous plate. The most temperature difference between experimental and numerical results is $5.2^{\circ} \mathrm{C}$. Comparison of experimental and numerical values of surface temperature for different Reynolds number and different water flow rate are shown in Figure 15-16.

\section{CONCLUDING REMARKS}

The present study is focused on investigation of heat transfer from a porous plate by cooling of air and surface with transpiration cooling. Surface and air temperature were used to calculate cooling efficiency of the system for different Reynolds number of hot gas stream (air) $(\mathrm{Re}=3035,3200,3300,3580,6500$ and 9430$)$ and mass flow rate of water as a coolant $\left(\dot{\mathrm{m}}_{\text {water }}=0.000083,0.000116,0.000166,0.000249,0.000498,0.000747\right.$ $\mathrm{kg} / \mathrm{s})$. The following conclusions can be drawn from the experimental and numerical results;

Increasing Reynolds number causes an increase on surface temperature and a decrease on cooling efficiency of porous plate and system. Increase of Reynolds number from $\mathrm{Re}=3035$ to 9430 causes a decrease on average cooling efficiency of porous plate of $7.9 \%$ and efficiency of the system of $13.7 \%$.

Increasing water flow rate caused a slight decrease on surface temperature and cooling efficiency of porous plate but a prominent increase on cooling efficiency of the system for the applied values of this study. By using transpiration cooling surface temperature can be decreased from $77^{\circ} \mathrm{C}$ to $28.6^{\circ} \mathrm{C}$. Increasing water flow rate nine times also causes an increase of $6.5 \%$ on efficiency of porous plate and an increase of $19.1 \%$ on cooling efficiency of the system.

Numerical results generally have a good approximation with experimental results. The most difference between experimental and numerical results is $5.2^{\circ} \mathrm{C}$.

Research areas for future investigations may be effect of particle diameter of porous plate on heat convection, effect of different coolant fluid on heat transfer, and understanding characteristics of thin film occurred on porous plate for heat transfer and fluid flow.

\section{ACKNOWLEDGMENTS}

This study was funded by the Scientific Research Council of Turkey (TUBITAK), with the program of postdoctoral scholarship (2219) and University of California Los Angeles Post Doctorate Program (UCLA/USA). Especially contributions of Prof. Vijay K. Dhir's Boiling Heat Transfer Laboratory are gratefully appreciated. 


\section{NOMENCLATURE}

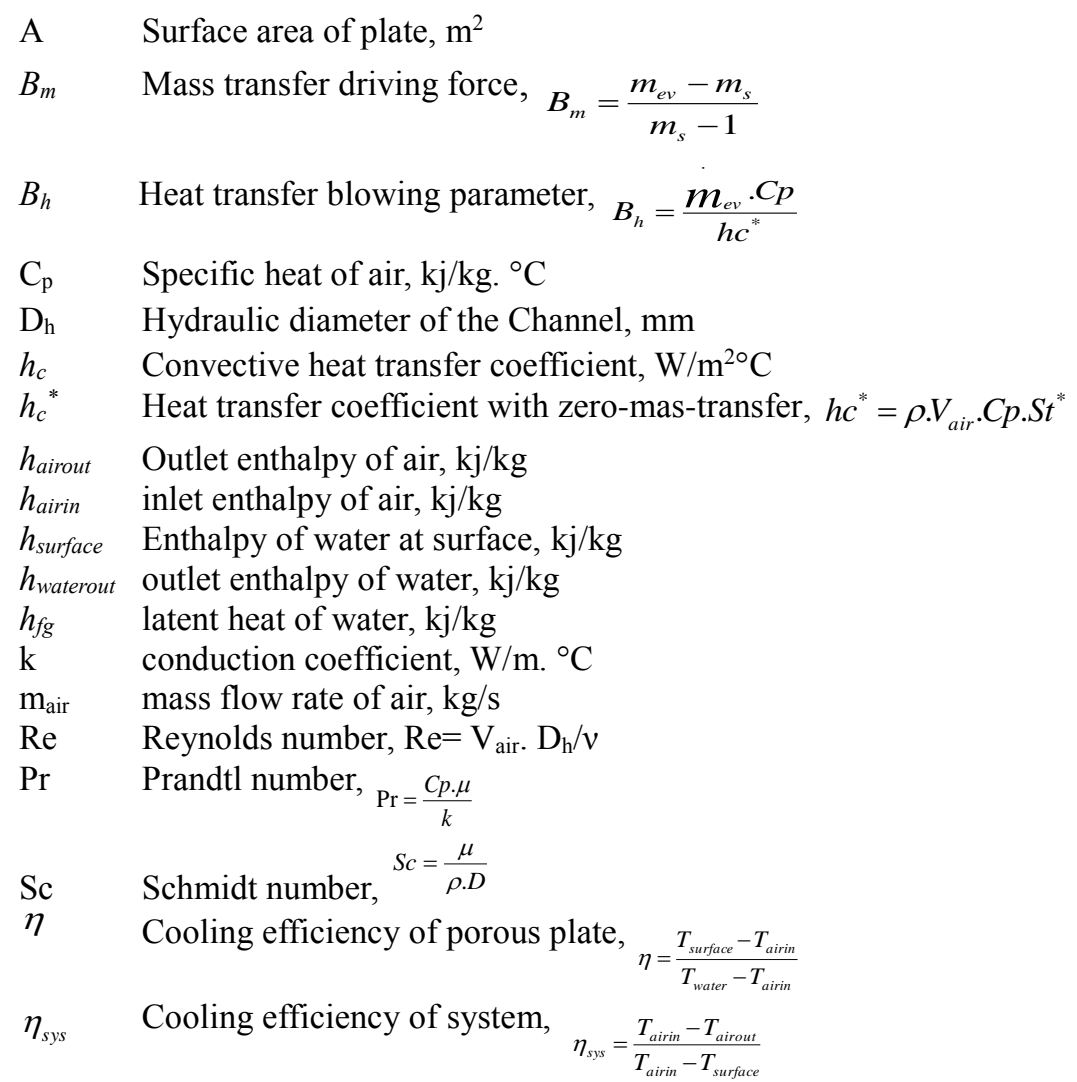

\section{REFERENCES}

[1] Polezhaev, J. The transpiration cooling for blades of high temperatures gas turbine. Energ. Convers Manage, 1997, 38, 1123-1133.

[2] Trevino, C.; Medina, A. Analysis of transpiration cooling of a thin porous plate in a hot laminar convective flow. Eur. J. Mech., 1997, 2, 245-260.

[3] Andoh, Y.H.; Lips, B. Prediction of porous walls thermal protection by effusion or transpiration cooling An analytic approach. Appl. Therm. Eng., 2003, 23, 1947-1958.

[4] Cerri, G.; Giovannelli, A.; Battisti, L.; Fedrizzi, R. Advances in effusive cooling techniques of gas turbines. Appl. Therm. Eng., 2007, 27, 692-698.

[5] Liu, Y.Q.; Xiong, Y.B.; Jiang, P.X.; Wang, Y.P.; Sun, J.G. Effects of local geometry and boundary conditions on transpiration cooling. Int. J. Heat Mass Tran., 2013, 62, 362-372.

[6] He, F.; Wang, J. Numerical investigation on critical heat flux and coolant volume required for transpiration cooling with phase change. Energ. Convers Manage, 2014, 80, 591-597.

[7] Huang, Z.; Zhu, Y.; Xiong Y.; Jiang P. Investigation of transpiration cooling for sintered metal porous struts in supersonic flow. Appl. Therm. Eng., 2014, 70, 240-249.

[8] Shi, J.; Wang, J. Optimized structure of two layer porous media with genetic algorithm for transpiration cooling. Int. J. Therm. Sci., 2008, 47, 1595-1601.

[9] Song, C.H.; Lee, D.Y.; Sung, T.R. Cooling enhancement in an air cooled finned heat exchanger by thin water film evaporation. . Int. J. Heat Mass Tran. 2002, 46, 1241-1249.

[10] Leu, J.S.; Jang, J.Y.; Chou, W.C. Convection heat transfer along a vertical heated plate with film evaporation in a non-Darcian porous medium. Int. J. Heat Mass Tran., 2009, 52, 5447-5450.

[11] Hsyan, S.M.; Jer, H.M.; Kuang, C.C. A study of the liquid evaporation with Darcian resistance effect on mixed convection in porous media. Int. Commun. Heat Mass, 2005, 32, 685-694.

[12] Maity, S. Thermocapillary flow of thin liquid film over a porous stretching sheet in presence of suction/injection. Int. J. Heat Mass Tran., 2014, 70, 819-826.

[13] Xin, C.; Rao, Z.; You, X.; Song, Z.; Han, D. Numerical Investigation of Vapor-liquid heat and mass transfer in porous media. Energ. Convers Manage, 2014, 78, 1-7.

[14] Sun, Y.; Zhang, L.; Xu, H.; Zhong, X. Flow boiling enhancement of FC-72 from microporous surface in mini channels. Exp. Therm. and Fluid Sci., 2011, 35, 1418-1426.

[15] Jiang, P.X.; Yu, L.; Sun, J.G.; Wang, J. Experimental and numerical investigation of convection heat transfer in transpiration cooling. Appl. Therm. Eng.,, 2004, 24, 1271-1289. 
[16] Liu, Y.Q.; Jiang, P.X.; Jin, S.S.; Sun, J.G. Transpiration cooling of a nose cone by various foreign gases. Int. J. Heat Mass Tran., 2010, 53, 5364-5372.

[17] Liu, Y.Q.; Jiang, P.X.; Xiong, Y.B; Wang, Y.P. Experimental and numerical investigation of transpiration for sintered porous flat plates. Appl. Therm. Eng., 2013, 50, 997-1007.

[18] Arai, M.; Suidzu, T. Porous ceramic coating for transpiration cooling of gas turbine blade. J. Therm. Spray Tech., 2012, 22, 690-698.

[19] He, F.; Wang, J.; Xu, L. Wang X., Modeling and simulation of transpiration cooling with phase change. Appl. Therm. Eng., 2013, 58,173-180.

[20] Wang, j.; Zhao, L.; Wang, X.; Ma, J.; Lin, J. An experimental investigation on transpiration cooling of wedge shaped nose cone with liquid coolant. . Int. J. Heat Mass Tran., 2014, 75, 442-449.

[21] Tsai, G.; Lin, Y.C.; Wang, H.W.; Lin, Y.F.; Su, Y.C.; Yang, T.J. Cooling transient in a sudden-expansion channel with varied rates of wall transpiration. Int. J. Heat Mass Tran., 2009, 52, 5990-5999.

[22] Langener, T.; Wolserdorf, J.; Selzer, M.; Hald, H. Experimental investigations cooling applied to C/C material. Int. J. Therm. Sci., 2012, 54, 70-81.

[23] Zhao, L.; Wang, J.; Ma, J.; Lin, J.; Peng, J.; Qu, D.; Chen, L. An experimental investigation on transpiration cooling under supersonic condition using a nose cone model. Int. J. Therm. Sci., 2014, 84, 207-213.

[24] Tsai, Y.Y; Lee, C.H. Experimental study of evaporative heat transfer in sintered powder structure at low superheat levels. Exp. Therm. Fluid Sci., 2014, 52, 230-238.

[25] Tsai, Y.Y; Lee, C.H. Effect of sintered structural parameters on reducing the superheat level in heat pipe evaporators. Int. J. Therm. Sci., 2014, 74, 225-234.

[26] He, S.; Guan, Z.; Gurgenci, H.; Hooman, K.; Lu, Y.; Alkhedhair, A.M. Experimental study of film media used for evaporative pre-cooling air. Energ. Convers Manage, 2014, 87, 874-884.

[27] Mills, A.F., Mass Transfer; 2nd ed., Prentica-Hall Inc.: New Jersey, 2001; pp. 153-169.

[28] Cengel, Y.A.; Ghajar, A.J. Heat and Mass Transfer; 4th ed., McGrew-Hill Education: New York, 2011; pp. 465-508. 